Society for the Anthropology of Work • Essential Labor

\title{
Sex Work during the COVID-19 Pandemic
}

\author{
Alex J. Nelson, Yeon Jung Yu, Bronwyn McBride
}

Published on: Nov 02, 2020

DOI: 10.21428/1d6be30e.3c1f26b7

License: Creative Commons Attribution 4.0 International License (CC-BY 4.0). 
The term essential labor has been adopted by governments worldwide to designate occupations without which the basic needs of citizens supposedly cannot be met. To date, no government has deemed the labor of sex workers to be essential, even in societies where sexual services are decriminalized or legalized. While many of the occupations deemed essential are experienced as degrading, inadequately remunerated, or insufficiently flexible, sex work remains an attractive occupation for many women, men, and gender-diverse people who either lack access to less stigmatized labor opportunities or find the stigma of sex work to be outweighed by other benefits. In this essay, as researchers with over two decades of combined experience studying sexual commerce, we provide an overview of how sex workers are adapting to the current COVID-19 pandemic, how they are being treated by governments and clients under quarantine, and what the pandemic can teach us about meeting sex workers' essential needs. Our account draws not only on media reports, but also on our observations and personal communications as we have monitored the sex industry over the past year.

\section{Transitioning to Virtual Sex}

During the pandemic, pornographic actors, escorts, exotic dancers, and professional dominatrices-at least those who have access to the Internet and a private workspace-are shifting toward virtual sexual services. A vast array of platforms exists for all forms of virtual intimacy, including preInternet mediums like phone sex and early Internet modes like sexting. However, two principal avenues for creating online commercial sexual intimacy are camming (that is, live video erotic performance) and the selling of self-made pornographic or erotic videos and images on third-party platforms. The majority of webcam models and erotic artists are concentrated in the United States, Europe, and Colombia, and they promote their services and cultivate their personas through mainstream social media websites like Twitter, Instagram, and Snapchat (Jones 2020).

After the pandemic began, platforms for webcam modeling and subscription-based erotic photo and video services began showing large increases in user traffic. During one week in May 2020, we found a 22 percent increase in models' streaming hours on a popular webcamming site. Approximately half of this increase reflected new content providers, while the other half reflected models streaming for additional hours when compared to a similar analysis we conducted in August 2019. Other cammingplatforms have confirmed even larger increases in sign-ups, with some as large as $\underline{75}$ percent. The transition to virtual work can also be seen among sex workers on Twitter, as escorts and exotic dancers shift to camming and/or erotic content creation by posting links to new subscription services to their social media followers.

Increased anxiety, loneliness, and a desire for human connection, exacerbated by social distancing measures, have created an ideal environment for online sex work to thrive and an expanded clientele for interactive erotic services and products. From our communications with online sex workers and 
observations of social media posts over the past several months, we have learned that, in response to market growth and increased competition, some webcam models and erotic artists who had engaged in virtual sex work well before the pandemic expanded their working hours so that they could maintain their earnings. Other workers told us that they increased their hours to capitalize on the higher-than-ever demand for online services, or to compensate for lost income outside of the sex industry due to the pandemic. Even though the increased competition and longer work hours pose challenges for all models, experienced models with established reputations and a regular clientele stand to fare better than newcomers who are only beginning to build a brand. While there may be an increase in overall demand, prospective clients are also subject to the financial burdens of the pandemic and are reportedly not spending as much on commercial sex as they were prior to COVID-19.

Shifting to virtual work is, however, not an option for all sex workers, since it generally requires broadband Internet, a webcam or filming equipment, and most importantly, a private space in which to work. Our observations of the online sex work sphere and of erotic content platform metrics highlight how some in-person sex workers with well-established client bases have been able to transition into virtual work, either by relying on existing customers or by drawing on their social media followings. In contrast, those who had yet to establish an online presence or who were engaged in forms of sex work that did not require one (such as massage parlor workers and street-based workers) often lacked the time, knowledge, and consistency needed to effectively grow and market their online personas. These workers are also likely to lack sufficient savings to weather the months of minimal income that a transitional period would entail, which has led some to continue to offer inperson sex services despite the potential risks presented by COVID-19.

While the demand for in-person encounters has declined globally due to lockdowns and restrictions on travel, sex workers continue to receive requests from clients. Some escorts who have chosen to (and been able to) stop working during the pandemic report pressure from clients to continue seeing them in person; those with few regulars may feel it necessary to see those clients to avoid losing their loyalty. Other sex workers are finding creative ways to continue offering in-person services safely. Australian brothel workers have suggested that the health risks of offering in-person services could be managed through precautions such as using hand sanitizer, instituting temperature checks, and disallowing group and oral sex. Other adult business owners have developed ways to offer their services while physically distancing. For example, one strip club in Portland, Oregon is adapting by converting itself into a drive-through service.

\section{Regulatory Responses to Transitions in Sex Work}

As governments and citizens grapple with how and when to resume public activity, the inclusion of sex workers and businesses in reopening plans and relief measures has varied. In Switzerland, where sex work is legal, sex work was allowed to resume on June 6, along with cinemas, nightclubs, and public 
pools, while sports and other activities said to involve "close and constant" contact remained prohibited. In contrast, brothel workers and independent escorts in New Zealand and the Netherlands have had to wait until the later stages of reopening. As of this writing, other countries like Australia have yet to clarify when and how sexual service providers will be permitted to continue operations. Such uncertainty adds to sex workers' anxiety and hinders their ability to financially plan or to determine the risks and rewards of operating in violation of lockdown orders.

Other pandemic protocols have had unintended consequences that are uniquely problematic for sex workers and their clients. In South Korea, for example, where the national contract tracing program has been effective overall, the lack of privacy that it affords has generated issues for sex workers and clients who are reluctant to account for all of the places they have been for fear of being outed for their involvement in stigmatized activities. If they test positive for COVID-19, the details of the places they have visited will be publicized. Even without personally identifying information, there is a chance that family, friends, or coworkers may be able to piece together clients' or workers' connection to the sex industry by their broadcasted location history, which is provided in app-based announcements of local COVID-19 patients. Some local governments in South Korea have also used the coronavirus as a pretext to crack down on sex venues like brothels and to permanently close red-light districts. A similar proposal advanced in India under the guise of reducing the spread of the virus has been criticized by sex workers, activists, and community organizations, as evidence suggests that such an approach would increase stigma and violence against sex workers by driving the services they provide underground.

Sex workers' access to emergency assistance has also varied from country to country. In Mexico, Japan, Thailand, Bangladesh, and France, sex workers have received aid from the government during the coronavirus lockdown, but only after advocacy by sex worker rights activists and allies. Adult businesses in the United States have had to sue for access to loans due to discrimination by business bureaus. In other countries, access to aid has depended on whether a sex worker has registered themselves, leaving out those who have not done so for fear of social detection or a permanent record of their criminalized work. In Germany, many sex workers have been excluded from aid because of their status as self-employed workers rather than employees. Worldwide, transgender sex workers, who face social and labor exclusion on the basis of their multiple marginalized identities and who are often less well remunerated than cis women, have been even more disadvantaged during the pandemic.

\section{Flexible Adaptation at the Margins of the Law}

As COVID-19 has posed new challenges for the sex industry, sex workers have navigated and adapted to the policy changes brought on by the pandemic, just as they have with previous epidemics like HIV. Given that sex work is criminalized in most countries and not considered legitimate labor, most social 
assistance systems exclude sex workers; thus, global sex worker rights organizations must work in innovative ways to compensate for the inadequacy of government aid. For example, many organizations in the United States and Canada have implemented community emergency hardship funds to provide a financial safety net to their most marginalized members; some have also provided direct support to those in urgent need through online crowdfunding initiatives. Informal forms of mutual aid and community resource distribution have also taken place offline between sex workers at a grassroots level.

Beyond weaving a financial safety net, sex workers have created both online and offline community spaces to access emotional support so as to cope with the insecurity presented by the pandemic. Experienced sex workers have provided newcomers with guidance on transitioning to online sex work. Others have leveraged online spaces to host live virtual events and performances to raise awareness of legislation that undermines sex workers' safety. While sex work may not be considered essential by governments across the globe, workers and the industry as a whole continue to adapt to the context of the pandemic just as sanctioned forms of essential labor have been forced to do. COVID19 has exacerbated the precarity of sex work, highlighting an urgent need to recognize sex work as legitimate work and, thereby, to safeguard sex workers' safety and economic stability. The pandemic represents an opportunity to reconsider evidence-based reforms to existing laws and policies, which

actively exclude sex workers and other informal, insecure, and criminalized workers from state social safety nets, and to uphold their labor and human rights.

\section{Author Bios}

Alex Nelson is a cultural anthropologist and Adjunct Assistant Professor in the Department of Anthropology at Appalachian State University. Since 2013, he has worked with Kathryn Hausbeck Korgan and Antoinette Izzo on the Erotic Entrepreneurs Project, a study of the business strategies of erotic escorts in the United States. He is also a contributor to the Virtual Sexual Economies Project, which examines the business strategies of adult web cam models and racial inequalities within the camming industry.

Yeon Jung Yu is a social and medical anthropologist with a background in public health, women's and gender studies, and East Asian studies. She received her $\mathrm{PhD}$ from Stanford University and is currently Assistant Professor at Western Washington University. Her research and teaching experience integrates a range of scholarly interests, including labor migration, HIV/AIDS, social stigma, marginalized populations, and social networks. Her work draws on extensive field research with"hidden" rural-to-urban migrant women working in the sex trade in contemporary China.

Bronwyn McBride is Postdoctoral Fellow at the Centre for Gender and Sexual Health Equity in Vancouver, Canada. She completed her $\mathrm{PhD}$ in July 2020 with the support of a Canadian Institutes of 
Health Research Doctoral Award; her doctoral research evaluated the impact of Canadian end-demand sex work laws and immigration policies on labor conditions and human rights among indoor and $\mathrm{im} /$ migrant sex workers in Vancouver.

\section{Preview Image}

Courtesy of Gilbert Mercier.

\section{Reference}

Jones, Angela. 2020. Camming: Money, Power, and Pleasure in the Sex Work Industry. New York: New York University Press. 